\title{
Setting Kerja Waktu Relay Arus Lebih pada Penyulang Kikim di Gardu Induk Sungai Juaro
}

\author{
Sarinah Agi Dia Savitri ${ }^{1}$, Feby Ardianto ${ }^{2}$, Bengawan Alfaresi ${ }^{3}$ \\ Jurusan Teknik Elektro Universitas Muhammadiyah Palembang \\ J1. Jendral Ahmad yani 13 Ulu Seberang Ulu II 13 Ulu, Kec. Plaju, Kota Palembang, Sumatera Selatan 30116 \\ ${ }^{1}$ sarinahagids@gmail.com \\ ardianto.feby@gmail.com \\ ${ }^{3}$ bengawan. alfaresi@gmail.com
}

Intisari - Gangguan-gangguan yang sering terjadi pada operasi sistem tenaga listrik dapat mengakibatkan terganggunya penyaluran tenaga listrik ke konsumen, sehingga menimbulkan arus hubung singkat yang cukup besar, untuk menghindari akibat gangguan tersebut diperlukan perlindungan jaringan dengan memasang suatu relay proteksi. Tujuan dari penelitian ini adalah melakukan simulasi menggunakan software ETAP dan perhitungan arus hubung singkat serta setting waktu kerja relay arus lebih. Metode yang digunakan untuk menganalisis gangguan hubung singkat yaitu 1) identifikasi data, 2) simulasi, 3) perhitungan, 4) hasil dan analisis serta 5) kesimpulan. Hasil penelitian, simulasi software ETAP arus gangguan hubung singkat maksimum pada jarak 25\% dengan arus gangguan tiga fasa sebesar $2877.341 \mathrm{~A}$, dua fasa sebesar $2672.708 \mathrm{~A}$, dan satu fasa sebesar $2491.835 \mathrm{~A}$. Gangguan minimum pada jarak $100 \%$ dengan arus gangguan tiga fasa sebesar 502.032 $\mathrm{A}$, dua fasa sebesar 434.671 A, dan satu fasa sebesar 347.035 A. Sedangkan untuk hasil simulasi waktu kerja relay arus lebih sisi incoming sebesar 1 detik dan sisi outgoing sebesar 0.55 detik, hasil perhitungan waktu kerja relay arus lebih sisi incoming sebesar 0.99 detik dan sisi outgoing sebesar 0.54 detik.

Kata kunci - Gangguan Hubung Singkat, relay arus lebih, ETAP Power Station 12.6.0.

Abstract - Interferences that often happen in an operation system of electric power can cause in disruption of distribution the electric power to consumers, so it causes quite large shor-circuit current. To avoid the impact of that inrerferences,setting relay portection to protect the network is needed. The purpose of the reserch is doing a simulation using ETAPsoftware, calculating the short-circuit current, and setting the working time of excess-current relay. The method that used to analyze the interferences of short-circuit current are : 1) data identifying, 2) Simulation, 3) calculation, 4) result and analysis and, 5) conclution. The results of the research show that the maximum interferences of short -circuit current at $25 \%$ of distance with three phase Interferences is $2877,341 \mathrm{~A}$, two -phase is $2672,708 \mathrm{~A}$, and one-phase is $2491,835 \mathrm{~A}$. The minimum Interferences at $100 \%$ distance with three phase Interferences is 502,032 A, two -phase is 434,671 $\mathrm{A}$, and one-phase is $347,035 \mathrm{~A}$. And the result of the simulation time of excess-current relay on incoming side is 1 second and on feeder side is $\mathbf{0 . 5 5}$ second, the results of the calculation working time of excess-current relay on the incoming side are 0.99 second and on the feeder, a side is 0.54 second

Keywords - short circuit, over current relay, ETAP power station 12.6.0 


\section{PENDAHULUAN}

Gangguan-gangguan yang sering terjadi pada operasi sistem tenaga listrik dapat mengakibatkan terganggunya penyaluran tenaga listrik ke konsumen. Gangguan merupakan sebuah keadaan dimana suatu sistem tenaga listrik yang sedang beroperasi mengalami keadaan yang tidak normal dan dapat mengganggu kontinuitas dari pelayanan tenaga listrik. Gangguan hubung singkat yang terjadi akan menimbulkan arus hubung singkat yang cukup besar, oleh karena itu diperlukan adanya suatu analisis terhadap parameterparameter yang berlaku pada sistem tenaga listrik jika gangguan hubung singkat tersebut terjadi, dan diperlukan suatu simulasi dengan menggunakan software ETAP power station untuk meneliti perubahan arus selama terjadinya gangguan hubung singkat. Untuk menghindari akibat gangguan tersebut diperlukan perlindungan jaringan dengan memasang suatu relay proteksi. Permasalah tersebut perlu dilakukan penelitian analisis setting OCR pengaman transformator Penyulang kikim Gardu Induk PT. PLN Sungai Juaro, untuk mensimulasikan gangguan hubung singkat pada sistem kelistrikan di Unit Gardu Induk Sungai Juaro menggunakan program ETAP Power Station 12.6.0.

\section{TINJAUAN PUSTAKA}

\section{A. Sistem Tenaga Listrik}

Sistem tenaga listrik adalah sistem penyediaan tenaga listrik bagi para pelanggan, diperlukan berbagai peralatan listrik yang terdiri dari empat bagian yaitu unit pembangkit, unit transmisi, gardu induk distribusi dan unit distribusi atau pemakai tenaga listrik.

Pembangkit tenaga listrik adalah bagian dari alat industri yang dipakai untuk memproduksi dan membangkitkan tenaga listrik dari berbagai sumber tenaga. Pembangkit tenaga listrik terdiri atas berbagai jenis pusat tenaga listrik, seperti Pusat listrik Tenaga Air (PLTA), Pusat
Listrik Tenaga Uap (PLTU) Pusat Listrik Tenaga Nuklir (PLTN), Pusat Listrik tenaga Gas (PLTG) dan Pusat Listrik Tenaga Diesel (PLTD). Transmisi tenag listrik merupakan proses penyaluran listrik dari pembangkit tenaga listrik. Sistem ini terbagi menjadi dua bagian, yaitu saluran udara (overhead line) dan saluran bawah tanah (underground) (Cekdin \& Barlian, 2013). Distribusi tenaga listrik adalah bagian sistem tenaga listrik yang paling banyak mengalami gangguan sehingga masalah utama dalam operasi sistem distribusi yaitu mengatasi gangguan. Sistem distribusi merupakan bagian yang paling dekat dengan pelanggan (Marsudi d. , 2015).

\section{B. Gangguan Hubung Singkat}

Gangguan hubung singkat merupakan gangguan yang bisa terjadi di dalam sistem tenaga listrik. Gangguan hubung singkat dapat merusak peralatan, seperti kumparan generator, transformator serta peralatan listrik lainya. Di dalam sistem tenaga listrik gangguan hubung singkat yang terjadi dapat dibedakan atas 3 macam gangguan, yaitu :

1. Gangguan hubungan singkat tiga fasa

2. Gangguan hubungan singkat dua fasa

3. Gangguan hubungan singkat satu fasa ke tanah

\section{Perhitungan Arus Gangguan}

\section{Hubunng Singkat}

Perhitungsn arus gangguan hubung singkat adalah analisis suatu sistem tenaga listrik pada saat terjadinya gangguan hubung singkat baik gangguan hubung singkat antar fasa dan gangguan hubung singkat fasa ke tanah. Analisis gangguan hubung singkat diperlukan untuk mempelajari sistem tenaga listrik baik waktu perencanaaan maupun setelah beroperasi (Hendriyadi, 2017).

\section{Perangkat Proteksi}

Perangkat proteksi atau sistem proteksi adalah susunan perangkat proteksi secara lengkap yang terdiri dari sekring, relay, dan perangkat lainnya untuk melakukan fungsi tertentu berdasarkan prinsip -prinsip proteksi sesuai dengan definisi yang terdapat pada standar IEC 6255-20. 


\section{E. Relay Proteksi}

Relay Proteksi adalah divais elektronik yang dirancang untuk merespon kondisi masukan dengan cara yang ditentukan dan setelah kondisi tertentu terpenuhi, menyebabkan operasi kontak atau perubahan mendadak serupa dalam hubungan sirkuit pengendali listrik. Sistem tenaga listrik memerlukan suatu relay proteksi, peralatan ini dibutuhkan apabila sistem mengalami gangguan atau kondisi tidak normal. Sistem proteksi merupakan cara mencegah atau membatasi keruskan peralatan akibat gangguan, sehingga kelangsungan penyaluran tenaga listrik dapat dipertahankan

Rele arus lebih (Over Current Relay) atau yang lebih dikenal dengan OCR adalah rele yang bekerja berdasarkan adanya kenaikan arus yang melebihi suatu nilai pengaman tertentu dan jangka waktu tertentu. Fungsi relai arus lebih

adalah untuk mendeteksi arus lebih yang mengalir dalam kumparan stator generator.

Menurut IEC 60255 terdapat 4 jenis karaktersitik standar standar yaitu Starndar Inverse (SI), Very Inverse (VI), Extremenly Inverse (EI) dan Definite Time (DT) . Pada umumnya hampir semua relay arus lebih dilengkapi dengan elemen penyetelan instantaneous.

Tabel 1 karakteristik kurva invers berdasarkan standar IEC

\begin{tabular}{cccc}
\hline Kurva karakteristik & $\beta$ & $\alpha$ & $\delta$ \\
\hline IEC Standard Inverse ( SI) & 0.14 & 0.02 & 1 \\
IEC Very Time Invese (VI) & 13.5 & 1 & 1 \\
IEC Long Time Inverse & 120 & 2 & 1 \\
(LTI) & & & \\
IEC Extremely Inverse (EI) & 80 & 1 & 1 \\
\hline
\end{tabular}

\section{F. Software ETAP}

ETAP merupakan software yang digunakan untuk melakukan desain / perencanaan sistem kelistrikan yang ada di suatu industri atau wilayah. Software ini sangat bermanfaat untuk melakukan berbagai analisa yang sangat membantu untuk mempermudah pekerjaan. ETAP mampu bekerja dalam keadaan offline untuk simulasi tenaga listrik, dan online untuk pengelolaan data real-time atau digunakan untuk mengendalikan sistem secara realtime. Fitur yang terdapat di dalamnya pun bermacam-macam antara lain fitur yang digunakan untuk menganalisa pembangkitan tenaga listrik, sistem transmisi maupun sistem distribusi tenaga listrik (Multa \& Aridani, 2013). Analisa sistem tenaga listrik yang dapat dilakukan ETAP antara lain :

1. Analisa aliran daya

2. Analisa hubung singkat

3. Starting motor

4. Koordinasi proteksi

5. Analisa kestabilan transien

ETAP memiliki dua macam standar yang digunakan untuk melakukan analisa kelistrikan, ANSI dan IEC. Pada dasarnya perbedaan yang terjadi di antara kedua standar tersebut adalah frekuensi yang digunakan, yang berakibat pada perbedaan spesifikasi peralatan yang sesuai dengan frekuensi tersebut. Simbol yang digunakan dalam analisa dengan mengunakan ETAP pun berbeda.

\section{METODE PENELITIAN}

Metode yang dilakukan terdiri dari lima tahapan yaitu:

1. Tahapan pertama berupa identifikasi data, tujuan tahapan ini adalah mengumpulkan data-data yang dibutukan untuk penetitian. Data yang diperlukan berupa data primer yaitu data trnasformator tenaga, data setting OCR dan data single line diagram Penyulang Kikim Gardu Induk Sungai Juaro..

2. Tahapan kedua berupa simulasi, pada tahapan ini dilakukan simulasi short circuit analysis dan setting waktu kerja relay OCR menggunakan software ETAP power station 12.6 .0 pada penyulang kikim gardu induk sungai juaro.

3. Tahapan ketiga berupa perhitungan, setelah melakukan simulasi, hasil dari simulasi short circuit analysis dan setting waktu kerja OCR akan di hitung kembali agar 
4. Tahapan keempat berupa hasil dan analisis, hasil yang didapat dari short circuit analysis dan setting waktu kerja relay akan di analisis sehingga didapat selisih antara hasil simulasi dan hasil perhitungan.

5. Tahapan kelima berupa kesimpulan dan saran, tujauan tahapan ini adalah untuk memberikan informasi kepada pembaca guna mengetahui secara cepat tentang apa hasil akhir yang diperoleh dari penelitian ini.

\section{HASIL DAN PEMBAHASAN}

\section{A. Analisis Arus Ganggua pada Penyulang Kikim}

Analisis arus gangguan hubung singkat pada penyulang kikim berupa analisis arus gangguan hubung singkat tersesar yang ada pada jarak $25 \%$ panjang penyulang dan arus gangguan hubng singkat terkecil berada pada jarak $100 \%$ panjang penyulang. Gambar 3 merupakan grafik arus gangguan hubung singkat penyulang kikim pada jarak 25\%, $50 \%, 75 \%$ dan $100 \%$ panjang penyula.

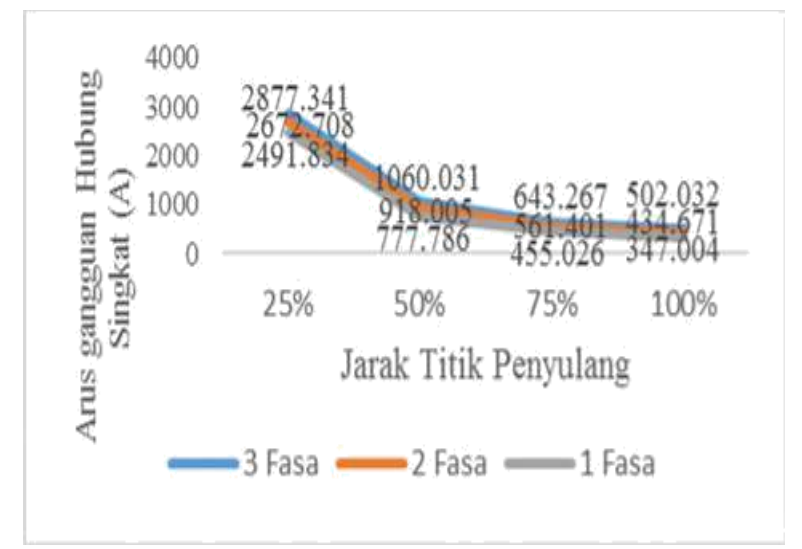

Gbr 1. Grafik arus gangguan hubung singkat Penyulang Kikim

Arus gangguan hubung singkat terbesar berada pada jarak $25 \%$ baik pada gangguan tiga fasa, dua fasa dan satu fasa sedangkan arus gangguan terkecil berada pada jarak $100 \%$ baik pada gangguan tiga fasa, dua fasa dan satu fasa. Dengan demikian besarnya arus gangguan hubung singkat dipengaruhi oleh jarak titik gangguan, semakin jauh titik gangguan maka semakin kecil arus gangguan hubung singkatnya. Hasil simulasi dan perhitungan terdapat selisih pembulatan angka desimal pada arus gangguan hubung singkan.

\section{B. Analisis Setting Waktu Kerja Relay OCR}

Analisis setting waktu kerja relay OCR pada penyulang kikim berupa analisis setting waktu kerja relay pada sisi incomig dan analisis setting waktu kerta relay pada sisi outgoing. gambar 4 merupakan grafik setting waktu kerja rely OCR

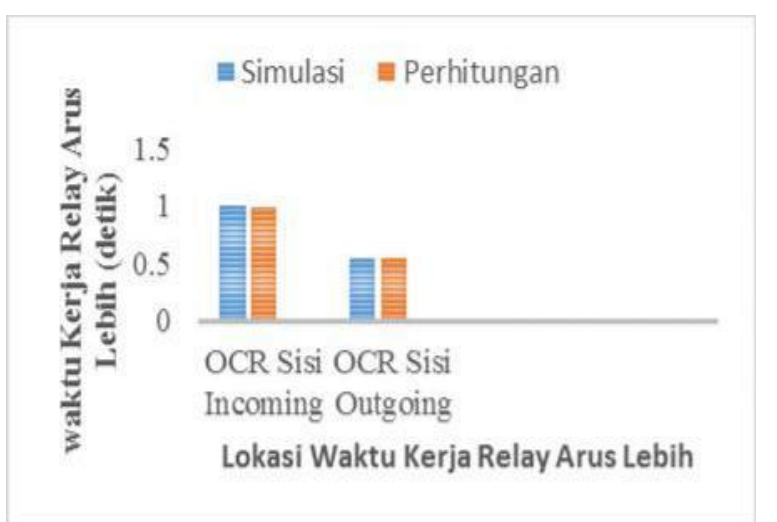

Gbr 2. Grafik setting waktu kerja relay OCR

Gambar 2 menunjukkan perbandingan hasil simulasi dan hasil perhitungan waktu kerja relay arus lebih disisi incoming dan disisi outgoing. Terdapat selang waktu antara relay arus lebih sisi incoming dan sisi outgoing. Dengan adanya selang waktu tersebut maka relay arus lebih sisi incoming dan relay arus lebih sisi outgoing tidak akan bekerja secara bersama. Relay arus lebih sisi outgoing mempunyai waktu kerja relay yang lebih cepat dari waktu kerja relay arus lebih disisi incoming

\section{PENUTUP}

Arus gangguan hubung singkat maksimum berada pada jarak 25\%, sedangkan arus gangguan minimum berada pada jarak $100 \%$ baik pada jenis gangguan tiga fasa, dua fasa dan satu fasa. Waktu kerja relay arus lebih disisi outgoing bekerja lebih cepat dari pada waktu kerja relay arus lebih disisi incoming, dikarenakan relay arus lebih pada sisi incoming sebagai relay cadangan sehingga relay arus lebih sisi outgoing bekerja terlebih dahulu. 


\section{REFERENSI}

[1] Cekdin, C., \& Barlian, T. (2013). Transmisi Daya listrik (Vol. 1). (F. S. Suyantoro, Ed.) Yogyakarta, Daerah Istimewa Yogyakarta, Indonesia: Andi.

[5] ATIHAN ETAP. YOGYAKARTA.
[2] Hendriyadi. (2017). PERHITUNGAN ARUS GANGGUAN HUBUNG SINGKAT PADA JARINGAN DISTRIBUSI DI KOTA PONTIANAK.

[3] Marsudi, d. (2015). OPERASI SISTEM TENAGA LISTRIK (3 ed.). Jakarta: Graha Ilmu.

[4] Multa, L., \& Aridani, R. P. (2013). MODUL PEL 